\title{
Modeling of Gas-Steel-Slag Three-Phase Flow in Ladle Metallurgy: Part II. Multi-scale Mathematical Model
}

\author{
Linmin $\mathrm{LI}^{1,2)}$ Baokuan $\mathrm{LI}^{1 / *}$ and Zhongqiu $\mathrm{LIU}^{1)}$ \\ 1) School of Metallurgy, Northeastern University, Shenyang, 110819 China. \\ 2) State Key Laboratory of Complex \\ Nonferrous Metal Resources Clean Utilization, Kunming University of Science and Technology, Kunming, 650093 China.
}

(Received on February 8, 2017; accepted on June 28, 2017; J-STAGE Advance published date: October 6, 2017)

\begin{abstract}
Gas stirring ladle is a complex three-phase reactor which contains phases whose interfaces are in different scales. The bubble-liquid interaction also leads to multi-scale eddy structures. The present work proposes a multi-scale mathematical model to simulate the multiphase flow in ladle, which directly captures large phase interfaces and eddies, while models sub-grid scale interfaces and eddies using respectively discrete bubble model (DBM) and one equation eddy viscosity model (OEEVM) in large eddy simulation (LES) approach. By this way, the mesh resolution can be defined relatively coarse to save computational resources. The volume of fluid (VOF) model coupled with the compressive interface capturing scheme for arbitrary meshes (CICSAM) is adopted for the slag surface, while the DBM is used for handling the dynamics of discrete bubbles. The bubble coalescence is considered using the O'Rourke's algorithm to solve the bubble diameter redistribution and it is found that aggregation mostly occurs below $0.2 \mathrm{~m}$ from the inlet. Moreover, bubbles are removed after leaving the air-liquid interface and the mass is transferred to air. The flow with multi-scale eddies induced by bubble-liquid interaction is solved using LES. The slag droplet entrainment and the slag-eye size fluctuation related with the pressure fluctuation on gas inlet are well revealed. The time-averaged spout eye size and the bubble diameter evolution are validated against the experimental data. The results show that the multi-scale VOF-DBM-LES model provides an effective modeling framework to predict the intrinsically unsteady flow behaviors in ladle.
\end{abstract}

KEY WORDS: ladle matellurgy; slag layer behavior; discrete bubble model; large eddy simulation; multiscale model.

\section{Introduction}

In argon gas stirring ladle, discrete bubbles that injected through porous plug (s) are used to remove inclusions and enhance the rates of refining reactions when they float, entrain the surrounding molten steel into their wakes and break-up the slag layer. The discrete bubbles go up desultorily, possibly aggregate with each other, and form a turbulent bubble plume with multi-scale eddies. With the transport of bubble plume and vortices, the slag layer would be broken through to form the spout eye and the slag droplet may be entrained. At a high gas flow rate, it is insufficient for the inverse flow to close the spout eye and a quasi-steady condition achieves to form a large spout eye, which is undesirable for the exposure of molten steel. Strong stirring is need to promote the efficiency of desulphurization and slag/ steel intermixing. On the other hand, a calm flow with small bubbles is needed for inclusion removal. To help understand the mechanisms of various phenomena invisible inside the ladle (e.g., mixing, spout-eye fluctuation, slag entrainment, inclusion transport) and improve the refining performance,

\footnotetext{
* Corresponding author: E-mail: libk@smm.neu.edu.cn DOI: http://dx.doi.org/10.2355/isijinternational.ISIJINT-2017-069
}

the application of CFD (Computational Fluid Dynamics) is needed to comprehensively depict the multi-phase flow features with bubble-liquid interactions and interfacial behaviors.

The interaction between the discrete bubbles and continuous fluids is one of the most crucial shortcomings of current multi-fluid models. Currently, numbers of mathematical models have been proposed to investigate the flow characteristics and slag layer behaviors in the gas stirred ladle. In an Eulerian way, Li et al. ${ }^{1)}$ and Llanos et al. ${ }^{2)}$ adopted the volume of fluid (VOF) approach to describe the fluid dynamics of all phases in ladle. Numerous works such as Zhang, ${ }^{3)}$ Bellot et al., ${ }^{4)}$ Mukhopadhyay et al., ${ }^{5)}$ Luo and $\mathrm{Zhu}^{6)}$ and Li et ll. $^{7)}$ used the Eulerian discrete fluid model with inter-phase interactions to simulate the bubble plume, and the population balance model (PBM) for calculation of non-uniform bubble size is also employed. ${ }^{5,7)}$ On the other side, Johansen and Boysan, ${ }^{8)}$ Guo et al. ${ }^{9)}$ and Madan et $a{ }^{10)}$ early proposed a Lagrangian form of Newton's second law for solution of bubbles in liquid, which is referred to as the discrete phase model (DPM). Recently, Liu et al. ${ }^{11)}$ and Cloete et al. ${ }^{12)}$ coupled the VOF and DPM respectively for the immiscible continuous phases and bubbles with the standard $k-\varepsilon$ turbulence model. For some other processes, 
also using the Lagrangian DPM for bubbles, Cho et al. ${ }^{13)}$ investigated the transient fluid flow during continuous casting of steel slabs, Ling et al. ${ }^{14)}$ investigated the effect of nozzle number on recirculation rate and mixing time in the $\mathrm{RH}$ process.

The VOF approach is an efficient way for modeling complicated free boundary configurations. ${ }^{15)}$ The results of Klostermann et al. ${ }^{16)}$ showed that VOF is suitable for rising bubble problems where bubbles are much larger than the grid size. Actually, as it is found in the experiment, ${ }^{7}$ bubbles injected by porous plug (s) are strongly dispersed in liquid, it is almost impossible to capture the bubble interface for a full-scale simulation. Though the Eulerian discrete fluid model coupled with the PBM provides a valid method for the non-uniform bubble diameter prediction, it still lacks the description of each individual bubble behaviors. Hengel et al. ${ }^{17)}$ applied coalescence and breakup models in a Lagrangian discrete bubble model (DBM) and validated it against the experimental PIV data of Deen et $a l .{ }^{18)}$ The DBM shows an effective capability for modeling micro-structured bubble columns in reactors. ${ }^{19)}$ Li et al. ${ }^{20,21)}$ investigated the transient flow features and bubble-liquids interactions in ladle using the VOF-DPM method and the large eddy simulation (LES) approach with and without considering bubble aggregation, bubbles are removed after the contact with air and the results are qualitatively compared with the experiment. From observation of slag layer fluctuation, large deformation and spout eye formation, a transient complex turbulent multiphase phenomenon is found. It is closely related to the multi-scale eddies induced by discrete bubbles. Simulations based on the ReynoldsAveraged Navier-Stokes (RANS) euqations are found to be inappropriate to describe the above mentioned unsteady phenomena. The LES approach, which resolves large eddies directly and models small eddies using the subgrid scale (SGS) model, is successfully taken into industrial applications for transient phenomena. ${ }^{20-23)}$

The diagrammatic sketch of gas bubble stirring process in ladle is displayed in Fig. 1, where the illustration of the

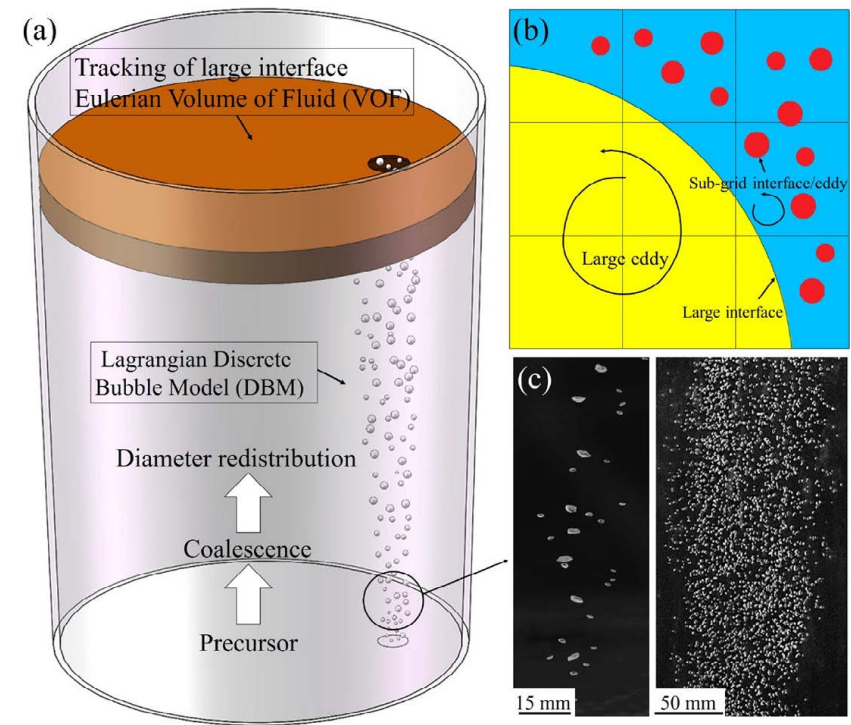

Fig. 1. Diagrammatic sketches of (a) refining process, (b) multiscale calculation approach and (c) captured bubble distribution in the experiment. (Online version in color.) multi-scale phenomenon is shown in Fig. 1(b), and the dispersed bubbles injected from the porous plug are shown in Fig. 1(c), the gas flow rates are $5 \mathrm{~L} / \mathrm{h}$ and $90 \mathrm{~L} / \mathrm{h}$ respectively, the bath height is $700 \mathrm{~mm}$ and the slag layer thickness is $50 \mathrm{~mm}$. It is seen that bubbles are quite small relative to the system, which makes it nearly impossible to fully resolve the bubbles by interface capturing methods. The present work aims to propose a multi-scale model for such system and give a detailed investigation into the unsteady slag layer behaviors associated with the bubble behaviors.

\section{Model Description}

As mentioned above, the system contains both large scale interfaces and small bubbles which can hardly be fully resolved at the same time. Thus, a multi-scale method by resolving the large interfaces based on mesh and modeling the subgrid scale bubbles using the Lagrangian approach is proposed. As for the turbulence, large eddies are also resolved directly and small eddies are modeled using the one equation eddy viscosity model (OEEVM). ${ }^{24,25)}$

There are two basic formulation schemes for the multiphase flow simulations: Eulerian-Eulerian formulation and Eulerian-Lagrangian formulation. The present model treats the continuous phases in a fixed or Eulerian frame of reference with capturing their interfaces, while the discrete bubbles are tracked in a Lagrangian frame of reference. For their coupling, the interphase forces between bubbles and continuous phases including drag, virtual mass and pressure gradient forces are considered. The bubbles will disappear and join to the air to be a continuum after contact with air, so the present model stops tracking the bubbles that reach the position where the air volume fraction is above 0.5 and then transfers the mass of bubbles to air.

\subsection{Compressive Interface Capturing VOF Model}

In VOF method, a single set of momentum equations is solved and the volume fraction of each fluid is tracked. An approach of compressive interface capturing scheme for arbitrary meshes (CICSAM) by Ubbink's work ${ }^{26)}$ is used, in which a supplementary interface-compression velocity $\boldsymbol{u}_{c}$ perpendicular to the interface is defined, by this way, the local flow steepens the gradient of volume fraction function and the interface resolution is improved. The conservation equation for volume fraction $(\gamma)$ of each fluid is solved in the following form:

$$
\frac{\partial \gamma}{\partial t}+\nabla \cdot(\gamma \boldsymbol{u})+\nabla \cdot\left(\boldsymbol{u}_{c} \gamma(1-\gamma)\right)=0
$$

where the last term on the left-hand side is known as the artificial compression term and it is non-zero only at the interface. The compression term stands for the role to shrink the phase-interface towards a sharper one. It does not bias the solution in any way and only introduces the flow of $\gamma$ in the normal direction to interface. The compression velocity is calculated as: ${ }^{27)}$

$$
\boldsymbol{u}_{c}=\min \left(C_{\gamma}|\boldsymbol{u}|, \max (|\boldsymbol{u}|)\right) \frac{\nabla \gamma}{|\nabla \gamma|}
$$

where $C_{\gamma}$ is a constant to control the intensity of compres- 
sion, which yields no compression if it equals to 0 and a conservative compression for $C_{\gamma}=1$. The surface tension is evaluated per unit volume using the continuum-surfaceforce (CSF) model: ${ }^{28)}$

$$
\boldsymbol{F}_{s}=\sigma \kappa \nabla \gamma
$$

where $\sigma$ is the surface tension coefficient and the curvature of the free surface $\kappa$ is calculated as:

$$
\kappa=-\nabla \cdot(\nabla \gamma /|\nabla \gamma|)
$$

\subsection{Large Eddy Simulation}

The rationale behind LES is a separation between large and small scales. The governing equations are obtained by filtering the time-dependent Navier-Stokes equations in the physical space. In contrast with RANS approaches based on solving for an ensemble average of the flow, LES naturally and consistently allows for medium and small scales transient flow structure. Starting from the incompressible Navier-Stokes equations, the governing equation of momentum balancing is described as follows:

$$
\frac{\partial \rho}{\partial t}+\nabla \cdot(\rho \boldsymbol{u})=0
$$

$$
\frac{\partial(\rho \boldsymbol{u})}{\partial t}+\nabla \cdot(\rho \boldsymbol{u} \otimes \boldsymbol{u})=-\nabla p+\nabla \cdot \boldsymbol{S}+\rho \boldsymbol{g}+\boldsymbol{F}_{s}+\boldsymbol{F}_{b} \ldots(6)
$$

where $\boldsymbol{S}=2 \mu \boldsymbol{D}$ with $\boldsymbol{D}=1 / 2\left(\nabla \boldsymbol{u}+\nabla \boldsymbol{u}^{\mathrm{T}}\right)$ is the viscous stress tensor, the properties used above are all mixture properties which are defined using the mixing law. $\boldsymbol{F}_{b}$ represents the forces due to bubble-liquid interactions acting on continuous phases. The LES equations are theoretically derived from Eq. (6) by low-pass filtering using a pre-defined filter kernel function $\phi=\phi(\boldsymbol{x}, \Delta)$ where $\Delta$ is the filter width. Thus, the filtered N-S equation can be described as:

$$
\frac{\partial(\rho \overline{\boldsymbol{u}})}{\partial t}+\nabla \cdot(\rho \overline{\boldsymbol{u}} \otimes \overline{\boldsymbol{u}})=-\nabla \bar{p}+\nabla \cdot(\overline{\boldsymbol{S}}-\boldsymbol{B})+\rho \boldsymbol{g}+\boldsymbol{F}_{s}+\boldsymbol{F}_{b} \ldots
$$

where over-bar denotes the filtered quantity. $\boldsymbol{B}$ is the subgrid stress tensor which can be written as: ${ }^{25}$ )

$$
\boldsymbol{B}=\rho \cdot(\overline{\overline{\boldsymbol{u}} \otimes \overline{\boldsymbol{u}}}-\overline{\overline{\boldsymbol{u}}} \otimes \overline{\overline{\boldsymbol{u}}}+\tilde{\boldsymbol{B}})
$$

where now only $\tilde{\boldsymbol{B}}$ needs to be modeled. The most common sub-grid modeling approaches utilize an eddy or sub-grid viscosity $v_{S G S}$ similar to the turbulent viscosity approach in RANS. In the present work, the one equation eddy viscosity model $(\mathrm{OEEVM})^{25)}$ is used.

\subsection{Discrete Bubble Model}

The trajectory of each bubble is calculated by integrating the force balance on it. The motion for each individual bubble is calculated from Newton's second law. The liquid phase contributions are taken into account via the forces experienced by each individual bubble. As the calculations are done for the cold experiments and the bath height is 0.7 $\mathrm{m}$, the maximum expansion rate of bubbles can be calculated as:

$$
\frac{V_{\text {top }}}{V_{\text {bottom }}}=\frac{p_{\text {bottom }}}{p_{\text {top }}}=\frac{p_{0}+\rho g h}{p_{0}}
$$

where $p_{0}$ represents the atmospheric pressure at room temperature. For $\mathrm{h}=0.7 \mathrm{~m}$, the result is 1.0677 , so the expansion of bubbles is not considered. For an incompressible bubble, the momentum equation can be described as:

$$
\frac{d \boldsymbol{u}_{\boldsymbol{b}}}{d t}=F_{D}\left(\boldsymbol{u}-\boldsymbol{u}_{\boldsymbol{b}}\right)+\frac{\boldsymbol{g}\left(\rho_{b}-\rho\right)}{\rho_{b}}+\boldsymbol{F}_{\boldsymbol{V} \boldsymbol{M}}+\boldsymbol{F}_{\boldsymbol{P G}} \ldots
$$

where $F_{D}\left(\boldsymbol{u}-\boldsymbol{u}_{\boldsymbol{b}}\right)$ is the drag force per unit bubble mass and the coefficient $F_{D}$ is written as:

$$
F_{D}=\frac{18 \mu}{\rho_{b} d_{b}^{2}} \frac{C_{D} \operatorname{Re}}{24}
$$

where $d_{b}$ is the bubble diameter and Re is the relative Reynolds number which is defined as:

$$
\operatorname{Re}=\frac{\rho d_{b}\left|\boldsymbol{u}_{\boldsymbol{b}}-\boldsymbol{u}\right|}{\mu}
$$

In the present work, bubbles are assumed spherical throughout the domain and the drag coefficient $C_{D}$ is calculated as: ${ }^{29)}$

$$
C_{d}=\left\{\begin{array}{cc}
0.424 & \mathrm{Re}>1000 \\
24\left(1+\mathrm{Re}^{2 / 3} / 6\right) / \mathrm{Re} & \mathrm{Re} \leq 1000
\end{array} .\right.
$$

The additional acceleration terms include the virtual mass force and pressure gradient force. They can be described as follows:

$$
\begin{gathered}
\boldsymbol{F}_{V \boldsymbol{M}}=C_{V M} \frac{\rho}{\rho_{b}}\left(\boldsymbol{u}_{\boldsymbol{b}} \nabla \boldsymbol{u}-\frac{d \boldsymbol{u}_{\boldsymbol{b}}}{d t}\right) \\
\boldsymbol{F}_{\boldsymbol{P G}}=\frac{\rho}{\rho_{b}} \boldsymbol{u}_{\boldsymbol{b}} \nabla \boldsymbol{u} \ldots \ldots \ldots \ldots
\end{gathered}
$$

where $C_{V M}$ is the virtual mass factor equal to 0.5 .

\subsection{Bubble Coalescence}

The present work considers the bubble coalescence and ignores the breakage because it is found that, in the present conditions with low Weber number, bubbles are relatively small and few bubbles break up when they going up in the experiment. The computational cost of a collision calculation which scales with the square of bubble number is prohibitive. This motivates the concept of parcels. Parcels are statistical representations of a number of individual particles. The O'Rourke's algorithm ${ }^{30)}$ together with the concept of parcels is a stochastic estimate of collisions. Once it is decided that two parcels of bubbles collide, the algorithm further determines the type of collision.

The probability of collision of two bubbles is derived from the point of view of the larger one, called the collector and identified with the character $i$. The smaller one is identified with the character $j$. The calculation is in the frame of reference of the larger bubble. If the smaller bubble passes within a flat circle around the collector of area $\pi\left(r_{i}+r_{j}\right)^{2}$ perpendicular to the trajectory, a collision will take place. 
Thus, the collision volume in one time step is defined as $\pi\left(r_{i}+r_{j}\right)^{2} u_{i, j} \Delta t$. The O'Rourke algorithm calculates the probability of collision as the ratio of collision volume and cell volume. For the collector and smaller bubble parcels with respectively $N_{i}$ and $N_{j}$ bubbles, the mean expected number of collisions for a collector is given by: ${ }^{31)}$

$$
\bar{\lambda}=\frac{N_{j} \pi\left(r_{i}+r_{j}\right)^{2} u_{i, j} \Delta t}{V_{\text {cell }}}
$$

where $V_{\text {cell }}$ represents the cell volume, $u_{i, j}$ represents the magnitude of relative velocity. The actual number of collisions that the collector experiences is not generally the mean expected number of collisions. The probability distribution of the number of collisions follows a Poisson distribution and it is defined as:

$$
P(n)=e^{-\bar{\lambda}} \frac{\bar{\lambda}^{n}}{n !}
$$

where $n$ represents the number of collisions between a collector and other bubbles.

Two uniform random numbers range in $[0,1)$ are assigned to determine the collision outcome. Firstly, a random number $x$ is assigned and only if $x>P(0)$ so that a collision can take place. ${ }^{32)}$ If a collision is taken place, the outcome should be determined. A second random number $y$ is assigned and the actual collision parameter is defined as:

$$
b=\left(r_{i}+r_{j}\right) \sqrt{y}
$$

which is compared to the critical offset:

$$
b_{\text {crit }}=\left(r_{i}+r_{j}\right) \sqrt{\min (1.0,2.4 f / W e)}
$$

where $W e$ is the collision Weber number defined as $W e=\rho u_{i, j}^{2} \bar{d} / \sigma$, and $f$ is a function of bubble size ratio defined as $\left(r_{i} / r_{j}\right)^{3}-2.4\left(r_{i} / r_{j}\right)^{2}+2.7\left(r_{i} / r_{j}\right)$. It is assumed that if

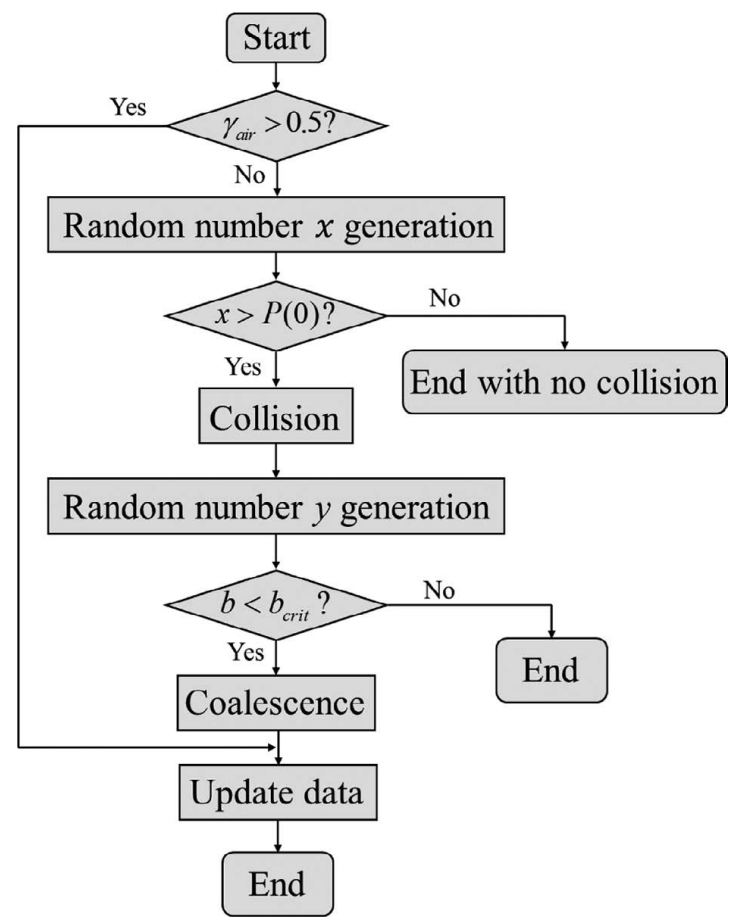

Fig. 2. Flow chart of bubble collision and coalescence algorithm. $b<b_{\text {crit }}$, a coalescence takes place, and the smaller bubble $j$ is deleted while the properties of bubble $i$ are determined according to the conservation laws: ${ }^{30}$

$$
\begin{array}{r}
m_{i}^{\prime}=m_{i}+m_{j} \ldots . \\
m_{i}^{\prime} \boldsymbol{u}_{i}^{\prime}=m_{i} \boldsymbol{u}_{i}+m_{j} \boldsymbol{u}_{j}
\end{array}
$$

Otherwise, a grazing collision occurs and the velocities of colliding bubbles are changed:

$$
\begin{gathered}
\boldsymbol{u}_{i}^{\prime}=\frac{m_{i} \boldsymbol{u}_{i}+m_{j} \boldsymbol{u}_{j}}{m_{i}+m_{j}}+\frac{m_{j}\left(\boldsymbol{u}_{i}-\boldsymbol{u}_{j}\right)}{m_{i}+m_{j}}\left(\frac{b-b_{\text {crit }}}{r_{i}+r_{j}-b_{\text {crit }}}\right) \ldots \\
\boldsymbol{u}_{j}^{\prime}=\frac{m_{i} \boldsymbol{u}_{i}+m_{j} \boldsymbol{u}_{j}}{m_{i}+m_{j}}-\frac{m_{i}\left(\boldsymbol{u}_{i}-\boldsymbol{u}_{j}\right)}{m_{i}+m_{j}}\left(\frac{b-b_{\text {crit }}}{r_{i}+r_{j}-b_{\text {crit }}}\right) \ldots
\end{gathered}
$$

When bubbles attach the liquid-air interface $\left(\gamma_{\text {air }}>0.5\right)$, we stop tracking the bubbles and the air volume fraction and velocity of the current cell is updated as:

$$
\begin{gathered}
\gamma_{\text {air }}=\gamma_{\text {air }}+V_{b} / V_{\text {cell }} \\
\boldsymbol{u}=\boldsymbol{u}+V_{b} \boldsymbol{u}_{b} / V_{\text {cell }} .
\end{gathered}
$$

The flow chart of the algorithm for bubble coalescence is shown in Fig. 2 for a more clear description.

\section{Numerical Details}

The simulations are performed for the water model experiment. The $\mathrm{N}_{2}\left(25^{\circ} \mathrm{C}, 1 \mathrm{~atm}\right)$ gas is injected into the liquid from a nozzle made of the porous mullite. The water and the soya bean oil are used to simulate the molten steel and the slag layer, respectively. The details about the geometric parameters and the material properties are shown in Table 1. As the bubbles are tracked in a Lagrangian reference frame, the mesh can be relatively coarse. The 3D all-hexahedral element mesh is determined as follows: the mesh size in vertical direction of the slag layer is set to 3 $\mathrm{mm}$ and the mesh size of the inlet is set to $6 \mathrm{~mm}$. The maxi-

Table 1. Parameters of simulations.

\begin{tabular}{cc}
\hline Parameters & Values \\
\hline Bottom diameter & $617 \mathrm{~mm}$ \\
Slope angle & $2.44^{\circ}$ \\
Water depth & $700 \mathrm{~mm}$ \\
Slag layer thickness & $\mathrm{mm}, 40 \mathrm{~mm}, 50 \mathrm{~mm}$ \\
Porous plug diameter & $43.4 \mathrm{~mm}$ \\
Plug radial position & $0.67 \mathrm{R}$ \\
Water density & $1000 \mathrm{~kg} \cdot \mathrm{m}^{-3}$ \\
Water viscosity & $0.001 \mathrm{~kg} \cdot \mathrm{m}^{-1} \cdot \mathrm{s}^{-1}$ \\
Oil density & $900 \mathrm{~kg} \cdot \mathrm{m}^{-3}$ \\
Oil viscosity & $0.058 \mathrm{~kg} \cdot \mathrm{m}^{-1} \cdot \mathrm{s}^{-1}$ \\
Gas density & $1.138 \mathrm{~kg} \cdot \mathrm{m}^{-3}$ \\
Gas viscosity & $1.663 \times 10^{-5} \mathrm{~kg} \cdot \mathrm{m}^{-1} \cdot \mathrm{s}^{-1}$ \\
Initial bubble diameter & $1 \mathrm{~mm}$ \\
\hline
\end{tabular}


mum mesh size of $15 \mathrm{~mm}$ and a stretching ratio of 1.1 is used. The mesh and boundary conditions are shown in Fig. 3. The number of total cells is about 400000 . The time step $\Delta \mathrm{t}$ is set to $1 \times 10^{-4} \mathrm{~s}$. For verifying the unsteady simulation results against the experimental results, the time-average procedure is presented to get the time-averaged results. The simulations are achieved using a workstation with two E5-2697v4 CPUs with a basic frequency of $2.3 \mathrm{GHz}$. For each case of simulation, 6 cores are used and it is stopped when the physical time achieves $50 \mathrm{~s}$.

The number of injected bubbles per unit time is calculated by the gas flow rate and the initial diameter:

$$
N_{i n}=\frac{6 Q}{\pi d_{b i}^{3}}
$$

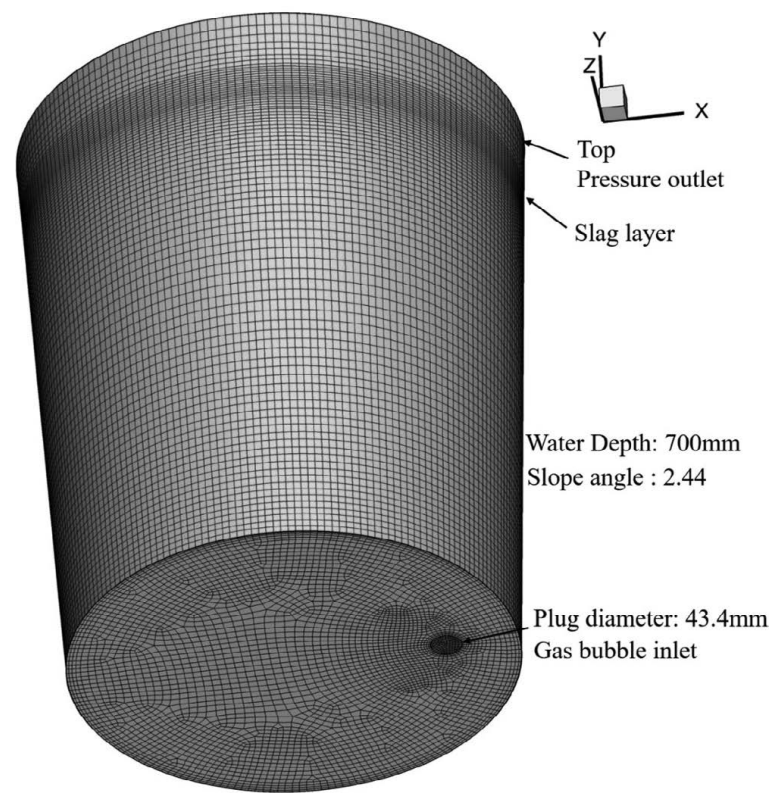

Fig. 3. The geometry size, mesh and boundary conditions. where $Q$ is the gas flow rate, and $d_{b i}$ is the initial bubble diameter, which is set to $1 \mathrm{~mm}$ according the experiment because it is found that the size of bubbles near the inlet and the smallest bubbles in liquid are about $1 \mathrm{~mm}$.

\section{Results and Discussion}

\subsection{Slag Layer Features and Slag Droplet Entrainment}

The slag layer features induced by bubbles spouting with the surrounding liquid is important to the refining process of desulphurization, slag/steel intermixing, inclusion removal, etc. The slag layer feature in the water model experiment is shown in Fig. 4(a) from different perspectives. The gas flow rate is $70 \mathrm{~L} / \mathrm{h}$ and the slag layer thickness is $50 \mathrm{~mm}$, which is the condition of a relatively calm stirring referred to as the critical gas flow rate. The instant shows that the slag layer is just broken through by water-bubble mixture, the lower surface of slag layer, especially at the periphery of spout eye, shows chaos with some slag droplets entrained. To better understand the mechanisms of slag layer fluctuation and slag droplet entrainment, the features of fluid flow and bubble transport are displayed in Fig. 4(b) with a time interval of $0.2 \mathrm{~s}$. The interface of slag layer is displayed using the iso-surface where the slag volume fraction is equal to 0.5 . The pictures also show the process that two droplets are dragged down and one of them quickly coheres with the slag layer when it contacts with the interface, while the other transports deeper into water. The velocity field shows that bubbles drive the liquid to go upward in chaos, numbers of vortices are induced under the slag layer as the liquid should turn down after reaching the top surface, and the vortices would extend around and transport to the periphery of the ladle. The vortices transport leads to the fluctuation of the lower surface and the downward liquid flow is the main factor of the slag droplet entrainment.
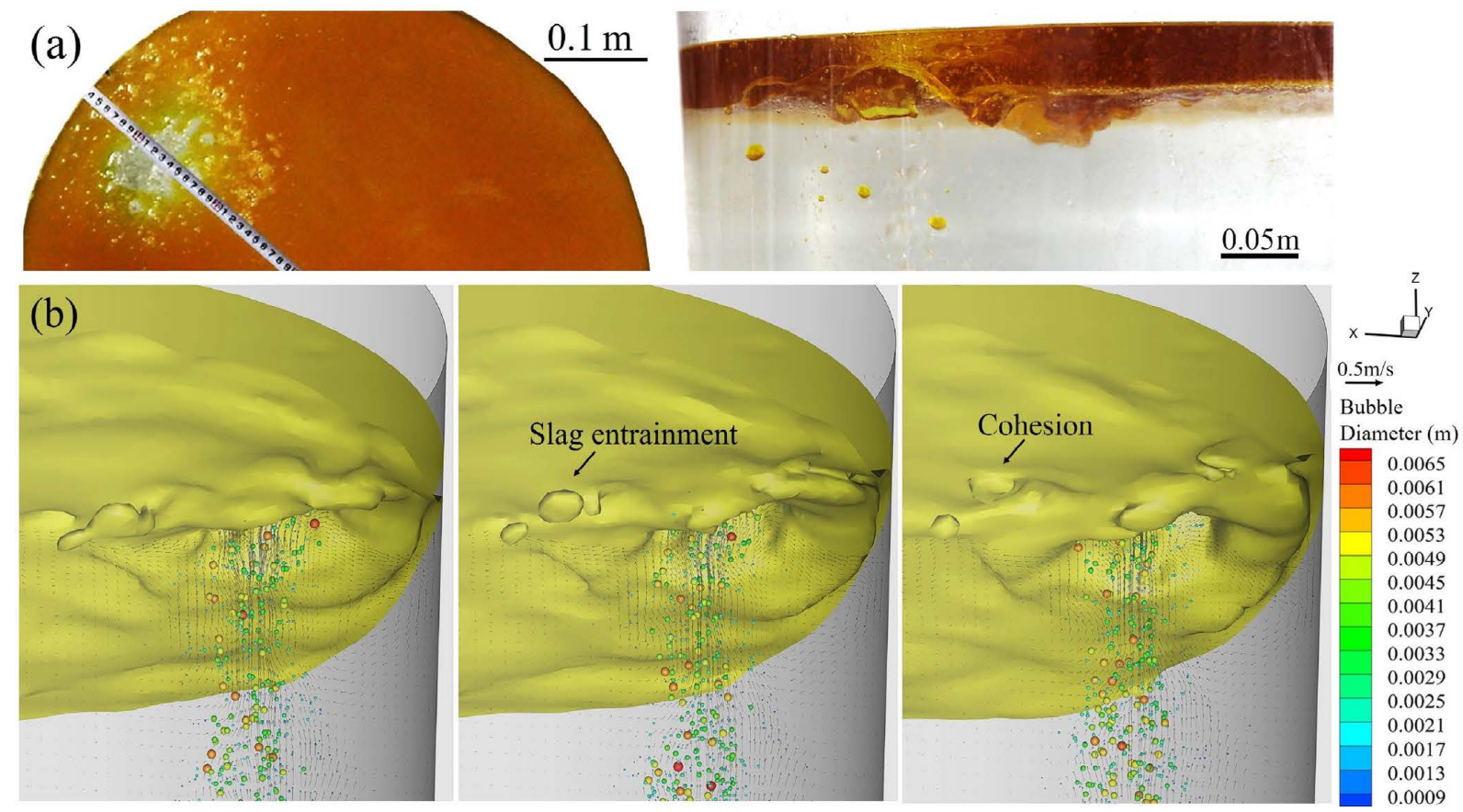

Fig. 4. Slag layer features and slag droplet entranment of (a) experiment and (b) simulation. (Online version in color.) 


\subsection{Spout Eye Variation and Inlet Pressure Fluctua- tion}

On the other hand, under the condition with the critical gas flow rate, the spout eye is found to form and collapse alternately with a quasi-period. Also the bubbling from the plug is found to have a periodic fluctuation. In order to find out the relationship between the spout eye variation and the bubbling fluctuation, the spout eye area variation and the inlet pressure fluctuation induced by the spouting bubbles are investigated in this section. Firstly, a typical period of spout eye open and close is shown in Fig. 5. The velocity vector is drawn near the top surface to show the flow of slag layer. It is shown that, as the liquid underneath the slag layer always takes the slag to the periphery, the slag on the top surface is flowing to the spout eye center to form a loop. The upwelling of bubble-water mixture would be drowned and the spout eye would be closed, alternately, but the process is not a simple cycle that the eye would sometimes last for a relatively long time and sometimes last for a short time. Besides, the bubble spouting also shows a periodic fluctuation which is found to be more regular. As marked at the lower part of bubble plume in Figs. 5(f)-5(h), bubbles are clustered and then dispersed to float again and again. The arrow marks a typical cycle that a "bubble cluster" is formed and dispersed. The period is found about $0.5 \mathrm{~s}$ in the figure.

To better understand the behaviors of spout eye variation and bubble spouting fluctuation, the pressure at the point $0.01 \mathrm{~m}$ above the plug are measured during the simulation using a "probe". The slag eye area proportion is recorded by a surface integral of the slag volume fraction over the plane near the top surface: $A_{e} / A_{0}=1-\left(\sum \gamma_{\text {slag }} A_{i}\right) / A_{0}$ where $i$ represents the cell on the plane and $A_{0}=0.362 \mathrm{~m}^{2}$. Figure 6 draws the curves of respectively (a) the differential pres- sure $\left(P-P_{0}\right)$ and (b) the eye area proportion $A_{e} / A_{0}$ fluctuation over time. As seen in Fig. 6(a), at the beginning, the pressure drops by $4 \mathrm{~Pa}$ and then increased by $4 \mathrm{~Pa}$, after 2
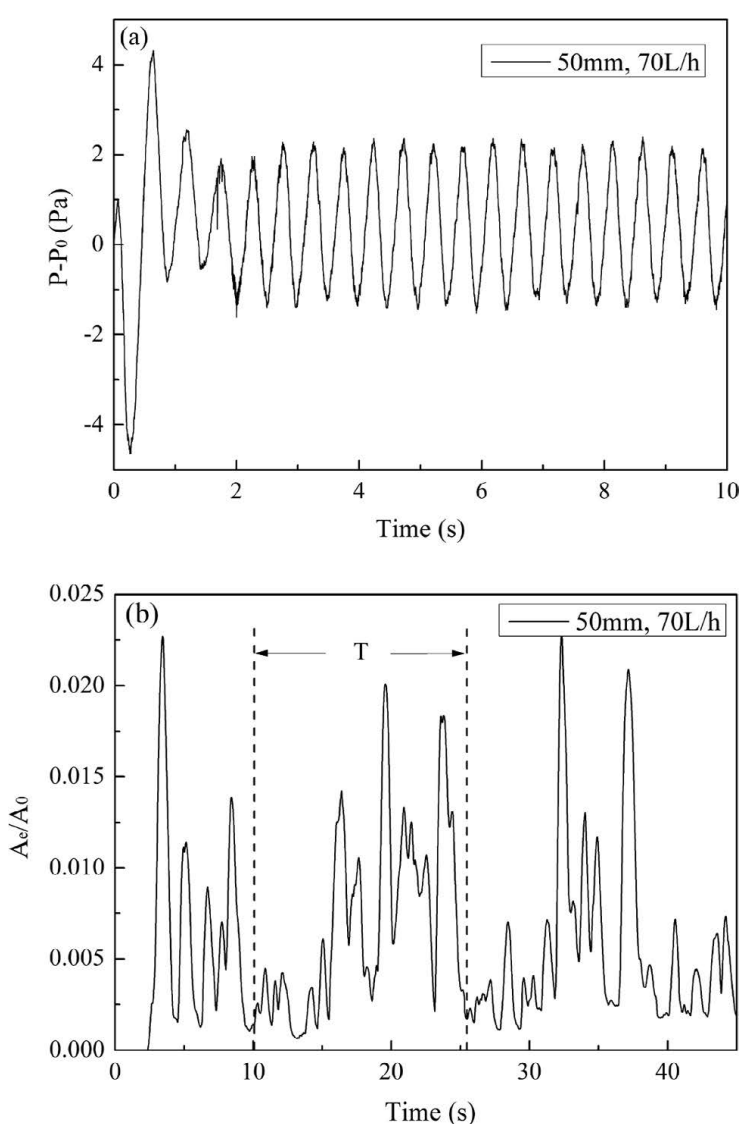

Fig. 6. (a) Inlet differential pressure fluctuation and (b) slag eye size fluctuation with the critical gas flow rate.
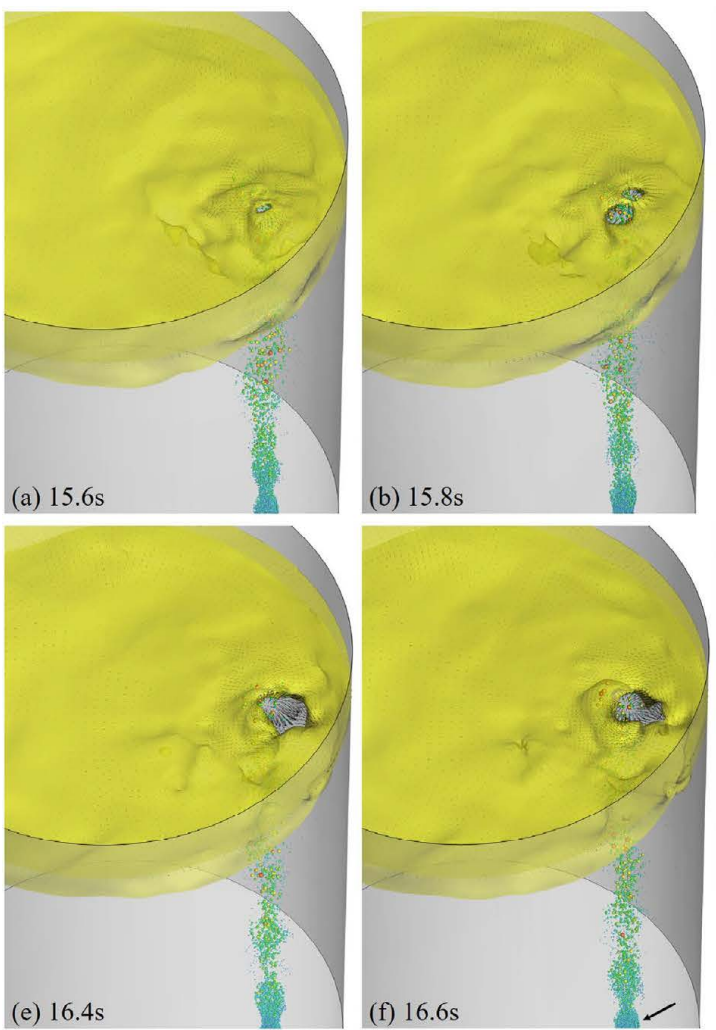
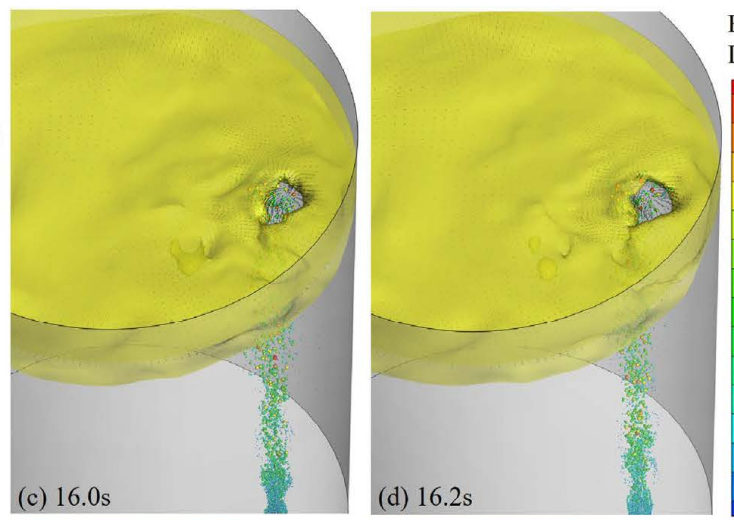

Bubble

Diameter (m)
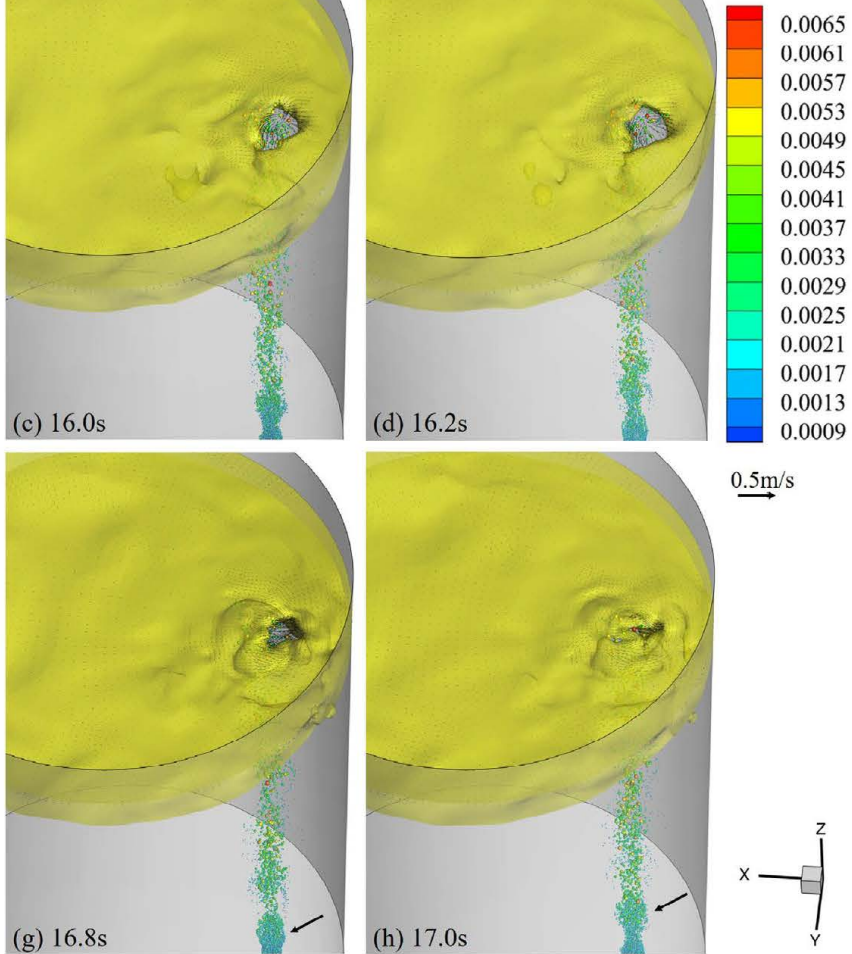

$\stackrel{0.5 \mathrm{~m} / \mathrm{s}}{ }$

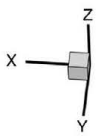

Fig. 5. A slag eye open and close process and the bubble plume features. (Online version in color.) 
seconds, the pressure fluctuation becomes quite regular with a range from $-2 \mathrm{~Pa}$ to $2 \mathrm{~Pa}$. Figure $6(\mathrm{~b})$ shows the slag eye area fluctuation over time. The eye area fluctuation shows complicated features, which include two main fluctuations. One is the fluctuation with a high frequency which is quite irregular, the other one is that the former fluctuation would fluctuate with a large range for a while and then with a small range for another while. A typical cycle for this kind of fluctuation is marked in Fig. 6(b) and the period T is about $15 \mathrm{~s}$.

In order to enable a quantitative analysis, the frequency spectrum is used for the measurements of pressure fluctuation and eye area fluctuation. Figure 7 plots the single-sided amplitude spectrums of both (a) differential pressure $\left(P-P_{0}\right)$ and (b) eye area proportion fluctuation $\left(A_{e} / A_{0}-A_{e, a v e} / A_{0}\right)$, by applying a fast Fourier transformation to the monitored signals. Obviously, the differential pressure fluctuation has a dominant frequency about $2 \mathrm{~Hz}$ as seen in Fig. 7(a), which is corresponding to that the period of pressure fluctuation is about $0.5 \mathrm{~s}$ as seen in Fig. 6(a). Due to the bubble-bubble interaction and bubble-liquid interaction, the bubble transport becomes irregular and makes the slag eye area fluctuation much more irregular as shown in Fig. 7(b). It is found that the frequency of the maximum amplitude is about 0.065 $\mathrm{Hz}$, which is corresponding to the marked fluctuation whose period is about $15 \mathrm{~s}$ as seen in Fig. 6(b).

\subsection{Effects of Gas Flow Rate and Slag Layer Thickness}

In the present simulations, two main parameters for the refining process is investigated: the gas flow rate and the slag layer thickness. For comparison between experiment
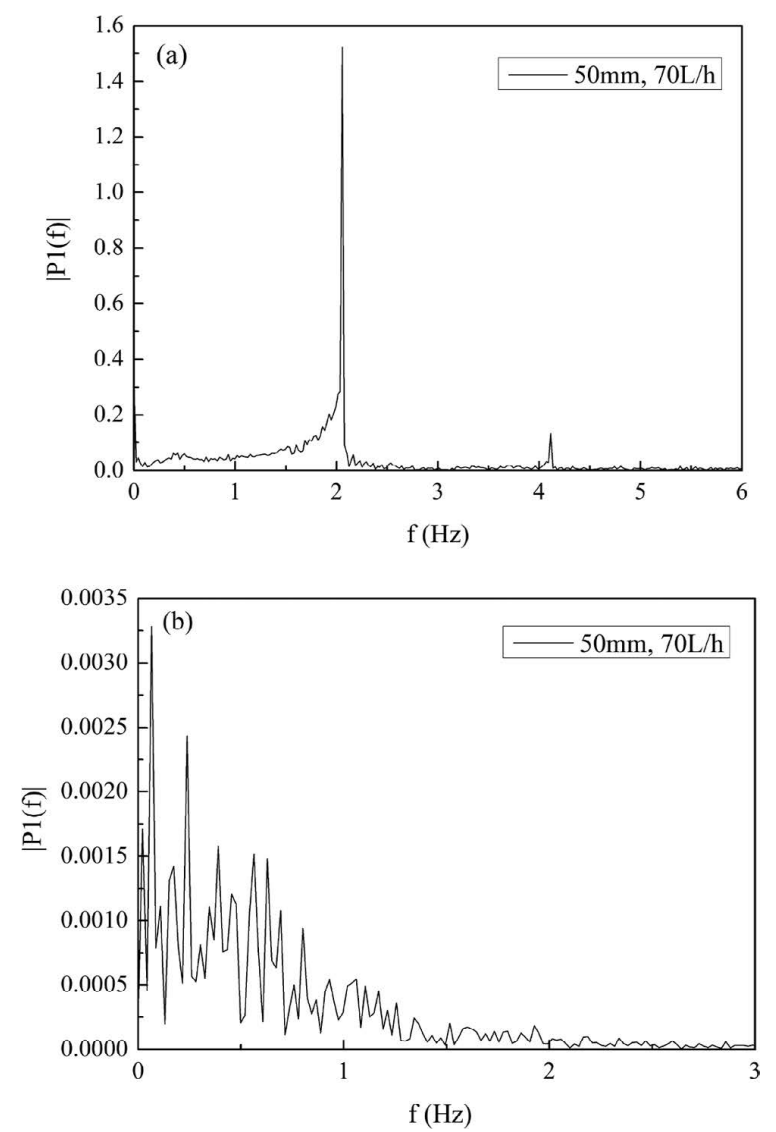

Fig. 7. Amplitude spectrums of (a) differential pressure fluctuation and (b) slag eye size fluctuation. and simulation, the time-average algorithm is presented for the fields of velocity, pressure and volume fractions. The time-averaged velocity and slag volume fraction fields are displayed in Fig. 8(a). The time-averaged velocity shows that the liquid in the region of bubble plume flows upward and turns down at the edge of spout eye. The slag on the lower surface is taken to the ladle periphery and that on the top surface is going to the spout eye. The time-averaged slag volume fraction counters with different gas flow rates and slag layer thicknesses marked in figures are compared with experimental observations which are at the status when the eye area is close to the average one. The numerical predictions agree qualitatively well to the observations.

Figures 9(a) and 9(b) show the effect of gas flow rate on the inlet pressure fluctuation. It is found that, with increasing gas flow rate, the fluctuation range increases and the frequency also increases as seen clearly in Fig. 9(b). The effect of slag layer thickness as seen in Figs. 9(c) and 9(d) is limited on the fluctuation range. And for the frequency, it decreases with increasing the slag layer thickness but the effect is also limited.

The slag eye area evolution is shown in Fig. 10 where Fig. 10(a) is the evolution with different gas flow rates and Fig. 10(b) is the evolution with different slag layer thicknesses. The straight lines are the time-averaged slag eye areas and the fluctuation is found to be quite irregular. With a higher gas flow rate, the eye area fluctuates around a larger value and the time-averaged eye area is found to increase linearly. As seen in Fig. 10(b), the influence of slag layer thickness is found great to the slag eye area. With decreasing the thickness, the eye size increases quickly. To get a quantitative comparison, the time-averaged slag eye areas with different operating parameters are compared to the experimental measurements. The eye area proportion is multiplied by the area of the sample surface $A_{0}=0.362 \mathrm{~m}^{2}$. The comparison is shown in Fig. 11 and a good agreement is obtained.

\subsection{Bubble Coalescence and Diameter Distribution}

A high speed camera is used to capture the spouting bubbles in the water model experiment so that it is available to observe the bubble behaviors including coalescence and breakup. It is observed that bubbles become quite dispersed when going upward as shown in Fig. 1(c). Details of the observations and the diameter measurements can be found in the authors' previous work. ${ }^{7}$ The present work uses the DBM for simulations of bubble transport, except for the bubble-liquid interactions, the bubble-bubble interactions can also be captured. Figure $\mathbf{1 2}$ continuously shows the process of bubble coalescence with a time interval of $0.004 \mathrm{~s}$ in the condition that the gas flow rate is $70 \mathrm{~L} / \mathrm{h}$. As marked, two bubbles are in contact and then coalesce into one bigger bubble. Figure 13 shows the bubble plumes in the whole system with different gas flow rates. The displayed bubbles are twice the size of the real ones. The maximum bubble diameter is about $6.5 \mathrm{~mm}$. As marked, it is found that bubbles are coalesced mostly in the region below $0.2 \mathrm{~m}$ from the inlet where bubbles are periodically gathered. With a higher gas flow rate, more large bubbles come out and they move upward faster. The time-averaged bubble diameter evolution along the center line of bubble plume is drawn in Fig. 14. 


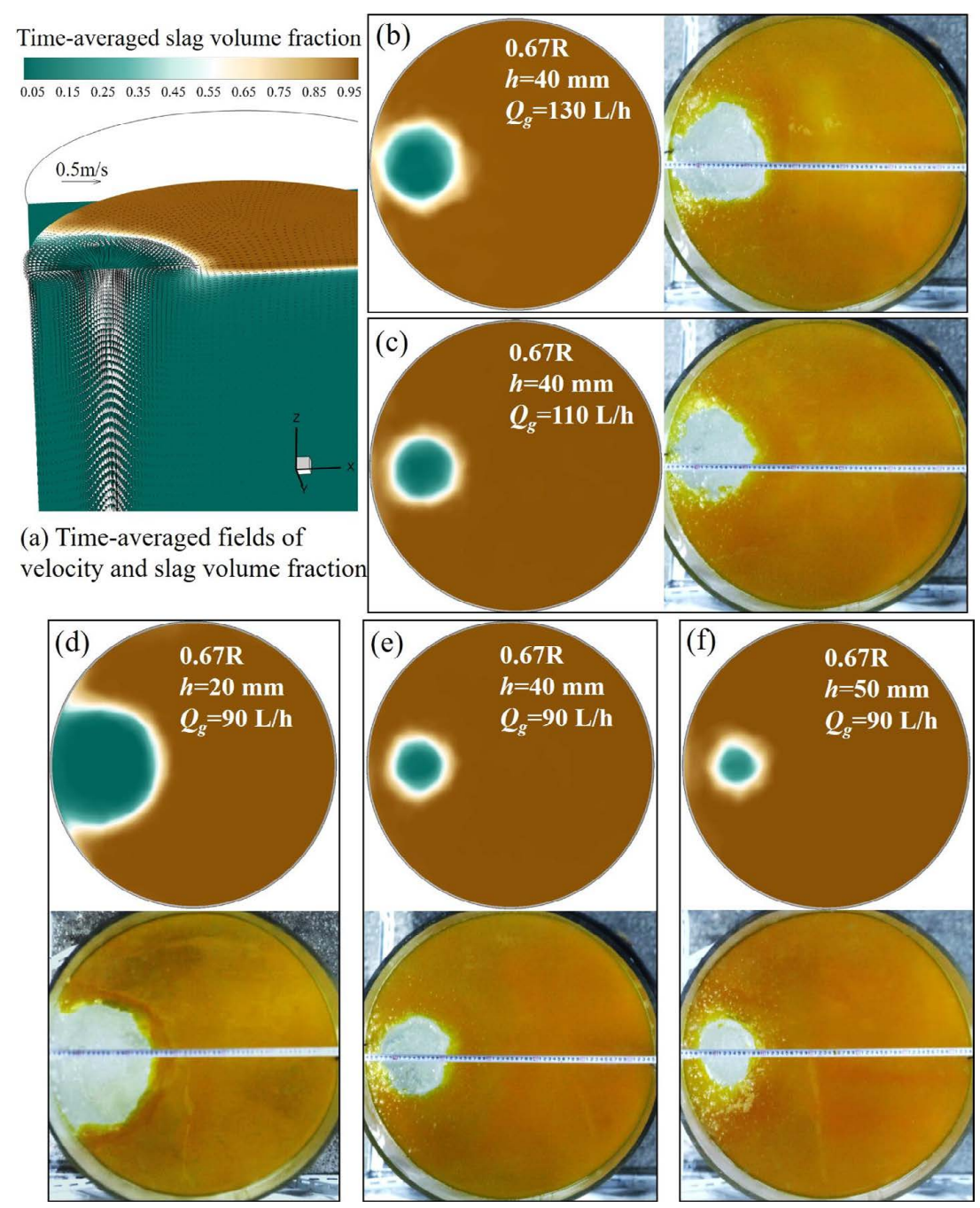

Fig. 8. (a) Time-averaged fields of velocity and slag volume fraction, comparison of time-averaged eye size between experiment and simulation with different gas flow rates: (b)-(e) and different slag layer thicknesses: (d)-(f). (Online version in color.)
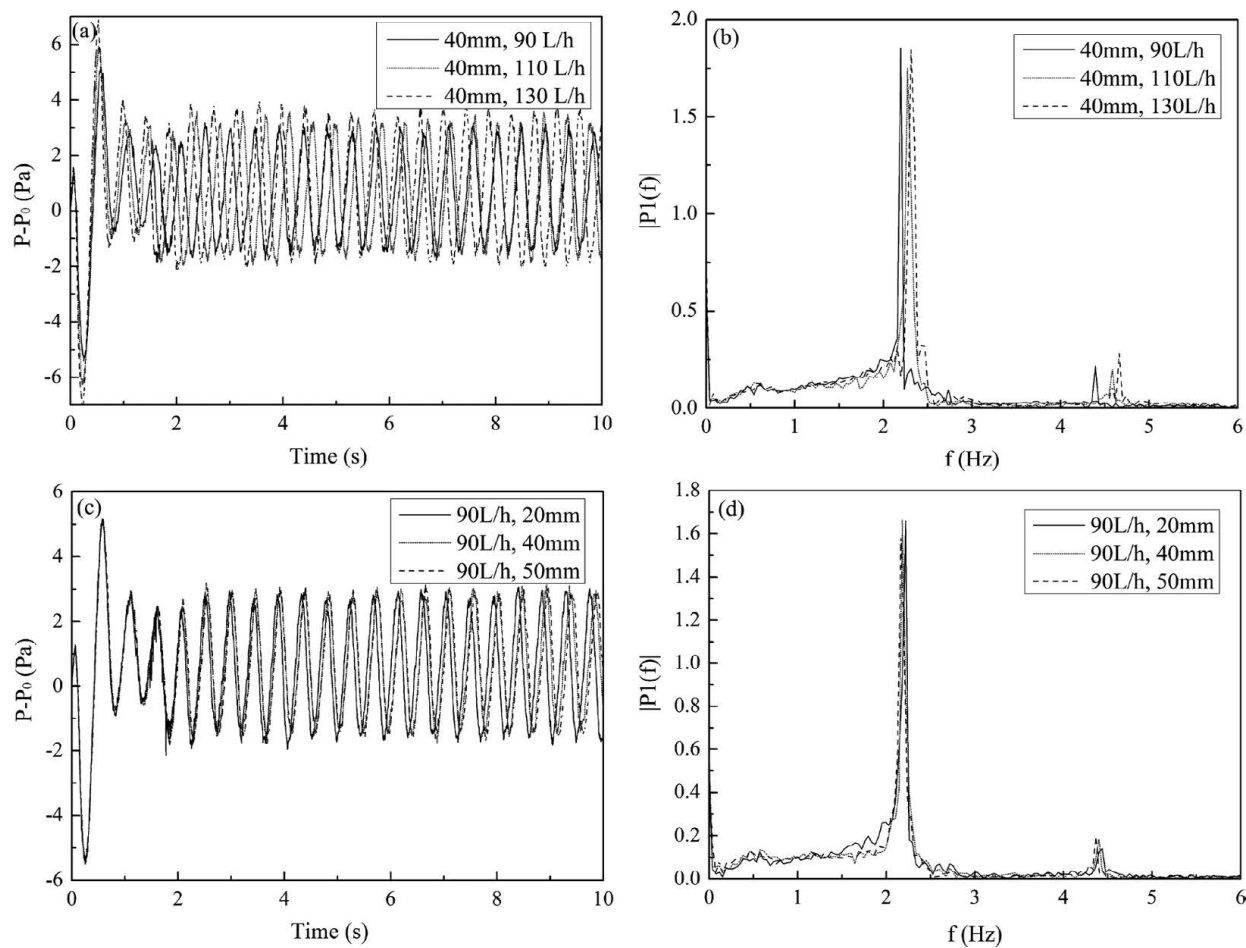

Fig. 9. Inlet differential pressure fluctuation and its frequency spectra with different gas flow rates: (a) and (b), and different slag layer thicknesses: (c) and (d). 

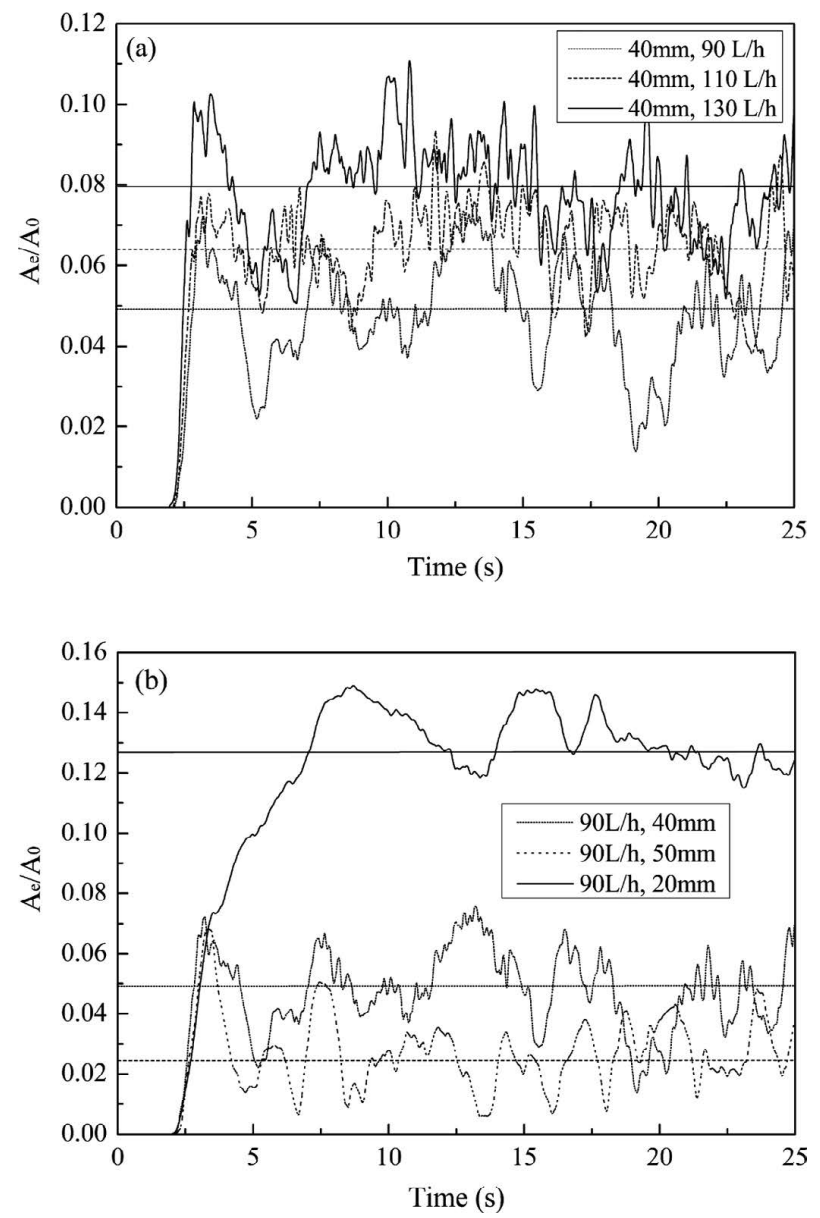

Fig. 10. Slag eye size fluctuation with different (a) gas flow rate and (b) slag layer thicknesses.

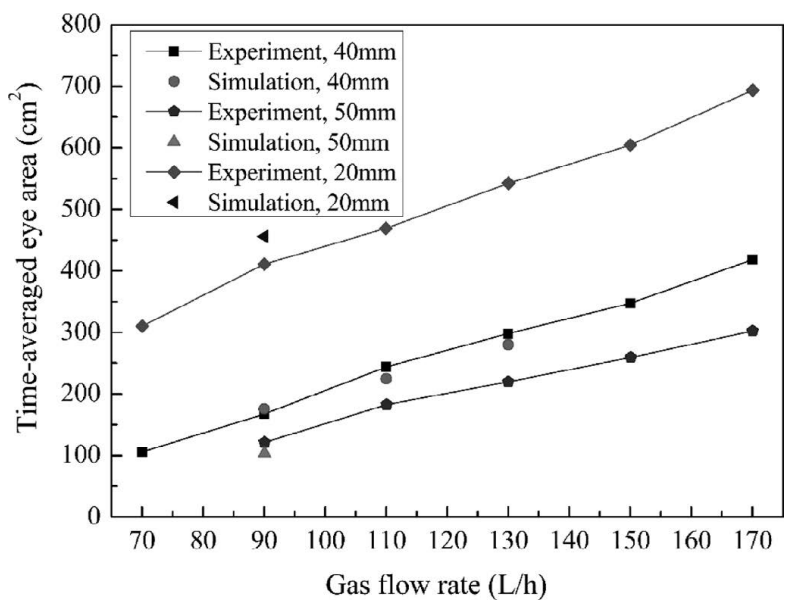

Fig. 11. Comparison of slag eye area between numerical and experimental results.
The present prediction is compared with both the experimental result and that predicted by the Eulerian method coupled with the PBM in our previous work. ${ }^{7)}$ It is shown that the result of the DBM is a bit larger than that of both the experiment and the PBM in the upper region. The reason may be that the present work ignores the lift force and the bubble breakage which have been considered in the Eulerian PBM. However, the results show reasonable agreement and it is also found that bubble diameter grows much faster below the height of $0.2 \mathrm{~m}$. After that, it changes little. The results show that the present model can track the trajectory of each bubble, look inside the bubble coalescence process, and predict an accurate bubble diameter evolution. More detailed works about the interphase forces and the bubble coalescence and break-up are needed in the future work.

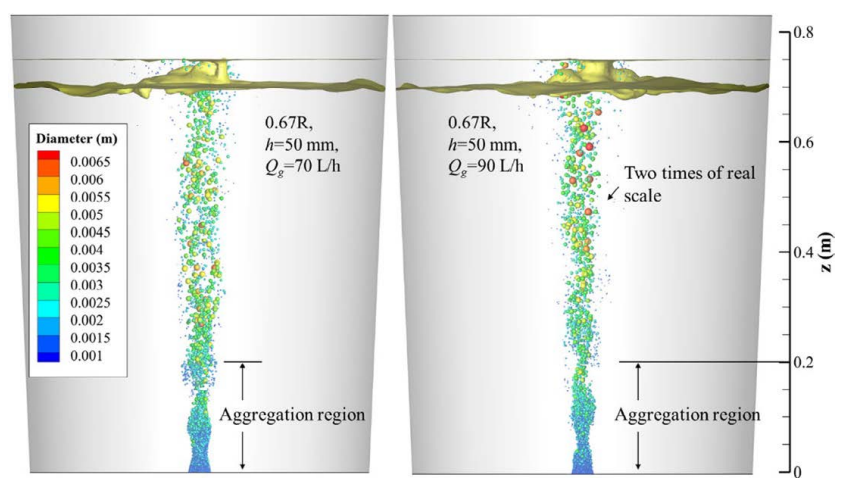

Fig. 13. Bubble plumes with different gas flow rates of (a) $70 \mathrm{~L} / \mathrm{h}$ and (b) $90 \mathrm{~L} / \mathrm{h}$. (Online version in color.)

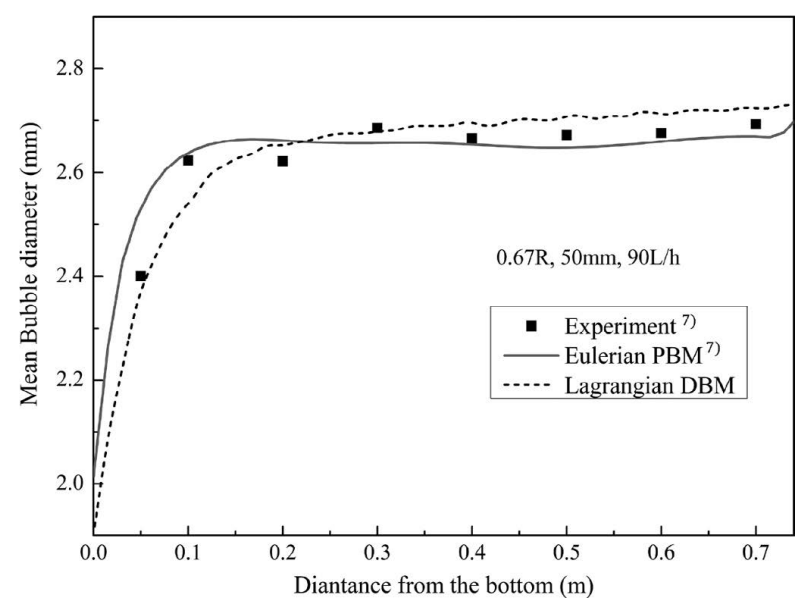

Fig. 14. Comparison of bubble diameter evolution among the experimental, ${ }^{7)}$ Eulerian $\mathrm{PBM}^{7)}$ and Lagrangian DBM results.

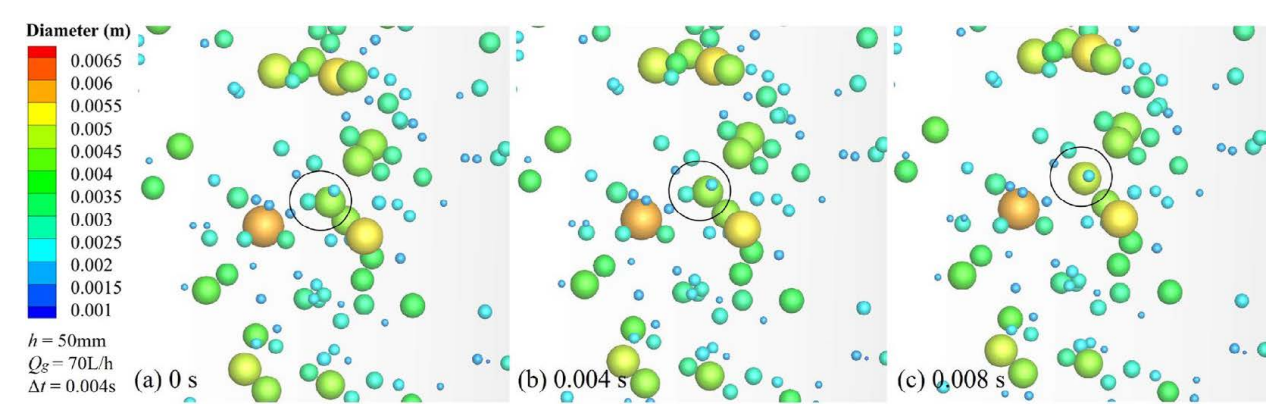

Fig. 12. Coalescence of Bubbles. (Online version in color.) 


\section{Conclusions}

A multi-scale mathematical model based on the LES and the DBM-VOF using the hybrid Eulerian-Lagrangian modeling approach is developed. The immiscible multi-fluid flow with bubbling in the ladle is simulated. The unsteady slag layer behaviors and the spout eye feautres are well revealed. The dispersed bubble behaviors are investigated by tracking the trajectory of each bubble and the coalescence is taken into account for the bubble diameter redistribution. The model is validated against the experiment and some conclusions can be drawn as follows:

(1) The present model can factually predict the transient phenomena of the refining process in ladle including the bubble transport and coalescence, inlet pressure fluctuation, slag layer fluctuation, slag droplet generation and spout eye features.

(2) The eddies induced by bubbles make the melt-slag interface fluctuate, and the downward flow may break up the slag into droplets with the effect of shear stress.

(3) At a high gas flow rate, a quasi steady state will be achieved to make the spout eye constantly exists and eye area fluctuate irregularly. At the critical gas flow rate, the slag eye open and close alternately, and two kinds of fluctuations is found: one is the fluctuation with a high frequency which is quite irregular, the other one is that the former fluctuation would fluctuate with a large range for a while, then fluctuate with a small range for another while, the frequency of the latter fluctuation is about $0.065 \mathrm{~Hz}$.

(4) The inlet pressure fluctuation is coresponding to the bubble periodic gathering behavior above the plug. The fluctuation frequency increases with increasing the gas flow rate and decreasing the slag layer thickness. The frequency of pressure fluctuation around $2-2.5 \mathrm{~Hz}$ is found.

\section{Acknowledgement}

Authors are grateful to the National Natural Science Foundation of China for support of this research, Grant No. 51574068 and 51604070. Thanks for the support of State Key Laboratory of Complex Nonferrous Metal Resources Clean Utilization, No. CNMRCUKF1607.

\section{List of symbols}
A: Area, $\mathrm{m}^{2}$
$b$ : Impact parameter, $\mathrm{m}$
$\boldsymbol{B}$ : Sub-grid stress tensor, $\mathrm{Pa}$
Co: Courant number
$C_{\gamma}:$ Model constant for CICSAM
$C_{d}$ : Drag force coefficient
$C_{V M}$ : Virtual mass force coefficient
$d$ : Bubble diameter, $\mathrm{m}$
$F_{D}$ : Momentum exchange coefficient
$\boldsymbol{F}_{b}$ : Bubble forces acting on liquids, $\mathrm{N} / \mathrm{m}^{3}$
$\boldsymbol{F}_{s}$ : Surface tension, $\mathrm{N} / \mathrm{m}^{3}$
$\boldsymbol{F}_{V M}:$ Virtual mass force, $\mathrm{m} / \mathrm{s}^{2}$
$\boldsymbol{F}_{P G}$ : Pressure gradient force, $\mathrm{m} / \mathrm{s}^{2}$
g: Gravitational acceleration, $\mathrm{m} / \mathrm{s}^{2}$
$h$ : Bath height, $\mathrm{m}$
$k_{S G S}: \quad$ Sub-grid scale kinetic energy
$m$ : Mass of individual bubble
$n$ : Number of collisions
$N$ : Number of bubbles
$p$ : Pressure, $\mathrm{Pa}$
$P: \quad$ Probability of collision
$Q$ : Gas flow rate, $\mathrm{m}^{3} / \mathrm{s}$
$r$ : Bubble radii, $m$
Re: Relative Reynolds number
$S$ : Viscous stress tensor, $\mathrm{Pa}$
$t$ : Time, $\mathrm{s}$
$\boldsymbol{u}$ : Velocity, $\mathrm{m} / \mathrm{s}$
$V$ : Volume, $\mathrm{m}^{3}$
$W e$ : Collisional Weber number
$x, y$ : Random numbers range in $[0,1)$

Greek letters
$\gamma$. Volume fraction
$\rho:$ Density, $\mathrm{kg} / \mathrm{m}^{3}$
$\sigma$ : Surface tension coefficient
$\mu$ : Viscosity, $\mathrm{kg} \mathrm{m}^{-1} \mathrm{~s}^{-1}$
$\kappa$ : Curvature of free surface
$\lambda$ : Expected number of collisions
$\Phi: \quad$ Flux through all faces of cell

\section{REFERENCES}

1) B. Li, H. Yin, C. Zhou and F. Tsukihashi: ISIJ Int., 48 (2008), 1704.

2) C. A. Llanos, S. Garcia, J. A. Ramos-Banderas, J. D. J. Barreto and G. Solorio: ISIJ Int., 50 (2010), 396.

3) L. Zhang: Modell. Simul. Mater. Sci. Eng., 8 (2000), 463.

4) J. P. Bellot, V. D. Felice, B. Dussoubs, A. Jardy and S. Hans: Metall. Mater. Trans. B, 45 (2014), 13.

5) A. Mukhopadhyay, E. W. Grald, K. Dhanasekharan, S. Sarkar and J. Sanyal: Steel Res. Int., 76 (2005), 22.

6) W. Lou and M. Zhu: Metall. Mater. Trans. B, 44 (2013), 1251.

7) L. Li, Z. Liu, B. Li, H. Matsuura and F. Tsukihashi: ISIJ Int., 55 (2015), 1337.

8) S. T. Johansen and F. Boysan: Metall. Trans. B, 19 (1988), 755.

9) D. Guo and G. A. Irons: Metall. Mater. Trans. B, 31 (2000), 1457.

10) M. Madan, D. Satish and D. Mazumdar: ISIJ Int., 45 (2005), 677.

11) H. Liu, Z. Qi and M. Xu: Steel Res. Int., 82 (2011), 440.

12) S. W. P. Cloete, J. J. Eksteen and S. M. Bradshaw: Miner. Eng., 46-47 (2013), 16.

13) S. M. Cho, S. H. Kim and B. G. Thomas: ISIJ Int., 54 (2014), 845.

14) H. Ling, F. Li, L. Zhang and A. N. Conejo: Metall. Mater. Trans. B, 7 (2016), 1950.

15) C. W. Hirt and B. D. Nichols: J. Comput. Phys., 39 (1981), 201

16) J. Klostermann, K. Schaake and R. Schwarze: Int. J. Numer. Methods Fluids, 71 (2013), 960.

17) E. I. V. van den Hengel, N. G. Deen and J. A. M. Kuipers: Ind. Eng. Chem. Res., 44 (2005), 5233.

18) N. G. Deen, T. Solberg and B. H. Hjertager: Chem. Eng. Sci., 56 (2001), 6341.

19) D. Jain, Y. M. Lau, J. A. M. Kuipers and N. G. Deen: Chem. Eng. Sci., 100 (2013), 496.

20) L. Li and B. Li: JOM, 68 (2016), 2160.

21) L. Li, Z. Liu, M. Cao and B. Li: JOM, 67 (2015), 1459.

22) Z. Liu, L. Li, B. Li and M. Jiang: JOM, 66 (2014), 1184

23) J. Zhang, S. Yang, J. Li, W. Yang, Y. Wang and X. Guo: ISIJ Int., 55 (2015), 1684

24) W. W. Kim and S. Menon: 35th Aerospace Sciences Meeting and Exhibit, American Institute of Aeronautics and Astronautics, Reno, (1997), AIAA-97-0210.

25) R. E. Bensow and C. Fureby: J. Turbul., 8 (2007), N54.

26) O. Ubbink: Ph.D. thesis, Imperial College, University of London, (1997).

27) H. G. Weller: Technical Report TR/HGW/04, OpenCFD, Bracknell, (2008), 1.

28) J. U. Brackbill, D. B. Kothe and C. Zemach: J. Comput. Phys., 100 (1992), 335.

29) A. B. Liu, D. Mather and R. D. Reitz: SAE Technical Paper 930072, SAE, Detroit, (1993), 1.

30) P. J. O'Rourke: Ph.D. thesis, Princeton University, (1981).

31) A. A. Amsden, P. J. O'Rourke and T. D. Butler: Technical Report LA-11560-MS, Los Alamos National Laboratory, Los Alamos, (1989), 1.

32) J. Zhang, J. Mi and H. Wang: Aerosol Sci. Technol., 46 (2012), 622. 